\title{
The Legal Language: Its Definitions and Applications in the Arabs Laws
}

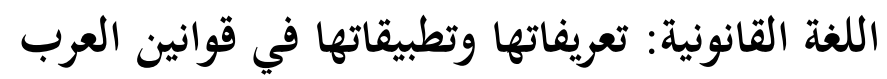

Adil Elshiekh Abdalla Ahmed

adil01@yahoo.com

Sultan Sharif Ali Islamic University

Brunei Darussalam

• Received: 29.08.2021 • Accepted: 18.10.2021 • Published online: 25.11 .2021

Abstract: This study deals with the definition of the legal language, its characteristics, its patterns and relationship to the general language, with the application of that in the Arabic language. The study paid attention to its applications in the Arabic language due to laxity of this type of language in the area of teaching Arabic. The study follows the descriptive analytical approach. The data of the legal document subjected to analysis and collected randomly from A rab legal and legislative publications. As the study shows, the legal language characterized with certain features that turned it to be different from the rest of the other types of language. These distinctive elements include amongst others: strangeness, ambiguity, excessive length of the sentence. Consequently, it seems to be too difficult and incomprehensible for those who are not specialized in laws, even though it is of the same normal language, and is subject to its phonemic, grammatical and semantic rules.

Keywords: Legal language, private language, law, Arabic language

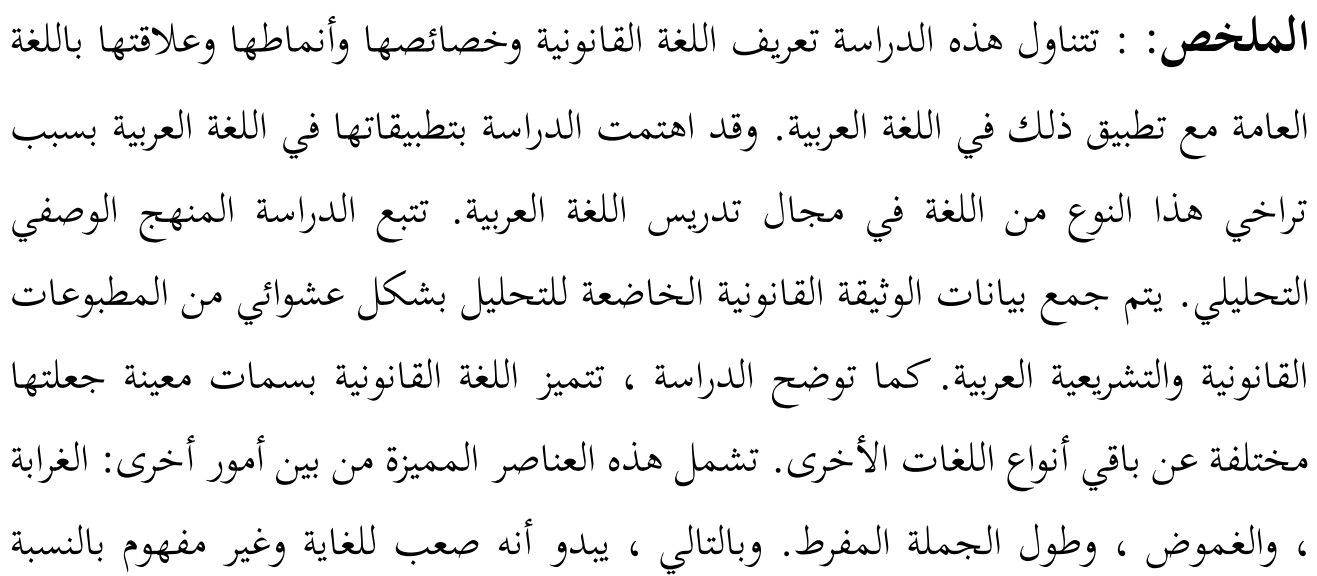

Copyright @ 2021 Author. Published Indonesian Journal of Arabic Studies 
Adil Elshiekh Abdalla Ahmed

لأولئك غير المتخصصين في القوانين ، على الرغم من أنها من نفس اللغة العادية ، وتخضع لقواعدها الصوتية والنحوية والدلالية.

كلمات دلالية: لغة قانونية ، لغة خاصة ، قانون ، لغة عربية.

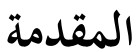

اللغة عنصر مهم في كل نشاط إنساني مجتمعي؛ فحيثما وجد مجتمع وجدت اللغة؛

إذ بدون اللغة في أشكالها المتعددة ينعدم التواصل البيني بين أفراد المجتمع، وينعدم كذلك فئك التواصل مع الأجيال السابقة واللاحقة؛ فلا يمكن تدوين تراث الإنسان ونقله كتابة أو شفاهة

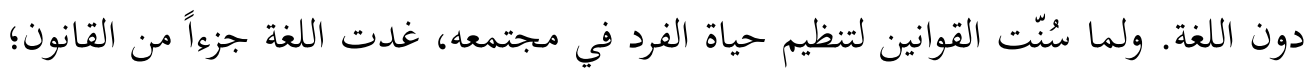
فبدونها لا يوجد قانون. فالقوانين التي هي بمثابة مجموعة من القواعد التشريعية، تصاغ باللغة، وتظل محكومة بها وبضوابطها حتى يصل إلى أفراد المجتمع؛ فيضبط وينظم سلوكهم؛ ولا يمكن أن يجقق القانون وظيفته إلا إذا خاطب المجتمع بلغته، ولا تكون اللغة مفهومة إلا إذا لها خضعت لقواعد وضوابط محددة (علوي) .

تقول شيلا هيات Sheila Hyatt إن الكلمات هي الأدوات الأساسية للقانون. ففي

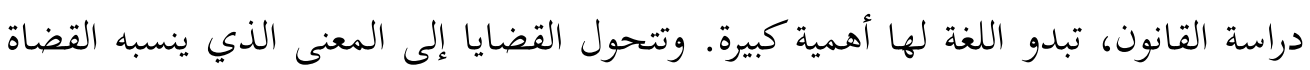
إلى الكلمات. بمعنى أن القضايا تتحول إلى نصوص وألفاظ؛ وعليه فإن رجل القانون يصور

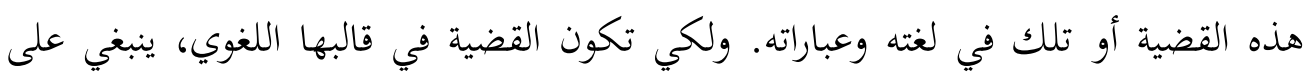
المحامين والقضاة استخدام الكلمات المناسبة؛ لتفعيل رغبات عملائهم.

إن العناية باللغة في الأحكام القضائية تغدو مهمة أهمية الحقيقة نفسها؛ لأن الحقيقة في الأحكام يُعبر عنها من خلال اللغة؛ حيث تأتي الأحكام القضائية مفسرة للنصوص القانونية ، بل إن المنطق يشكل في معظم الأحيان وسيلة إقناع، واقتناع في مضمون الحكم القضائ القصائي؛

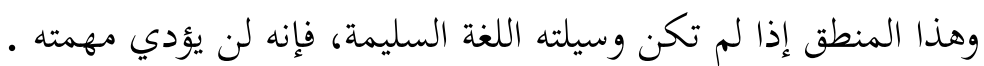
لهذا كان علماء السلف يعتنون باللغة في مسائل الفقه؛ فقد كان أبو الحسين أحمد بن فارس بن زكريا واسع الآداب، متبحرًا في اللغة العربية، وكان يناظر في الفقه، وينظر مذهب 
Adil Elshiekh Abdalla Ahmed

مالك، ويناظر في الكلام، وينصر مذهب أهل السنة، وطريقته في النحو طريقة الكوفيين؛ وإذا وجد فقيهًا أو متكلمًا أو نحويًا يأمر أصحابه بسؤالهم إياه ويناظر في مسائل من جنس العن العلم

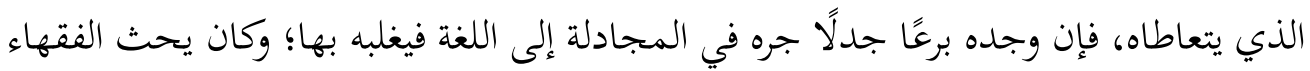
دائمًا على اللغة ويلقي عليهم مسائل، ذكرها في كتاب سماه "فتيا فقيه العرب" ويخجلهم بذلك ليكون الخجل لهم داعية إلى حفظ اللغة ويقول: المن قصر علمه في اللغة غولط فغلط"

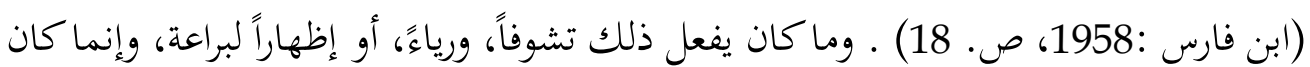
قاصداً بذلك لفت أولئك الفقهاء إلى أهمية اللغة، ومكانتها في مجالاتهم العلمية؛ فيطورونها . وحين تكلم فقهاء الشريعة - رحمهم الله - عن شروط الاجتهاد والفتوى ذكروا جملة من الشروط والمعارف التي يجب أن تتوافر في الفقيه حتى يكون من أهل الاجتهاد والفتوى. وهذه الشروط عند التأمل ترجع كلها إلى نوعين من المعارف لابد للفقيه أن يحيط بها وهما: 1- المعارف اللغوية. 2- المعارف الشرعية" (الجذلاني،2009). "إن إعمال قواعد الإقناع والاقتناع هو الذي يضفي المصداقية الحقيقية للأحكام القضائية، وهذه تقوم بشكل أساسي على توظيف الأسلم والأصح في صياغة الأحكام، هذه

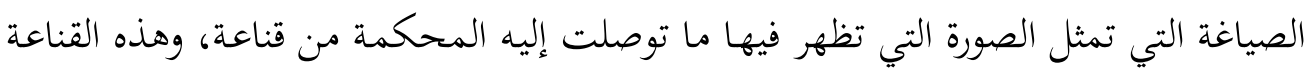

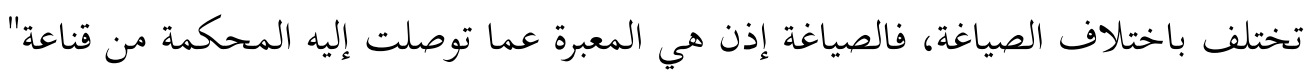

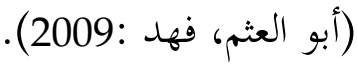
نتائج الدراسة وتحليلها اللغة القانونية هي هي جنس مما يطلق عليه اللغويون اللغة الخاصة. وهي عين ما يطلق عليه اللغويون اللهجات الاجتماعية socio-dialect والتي هي نوع من اللغة مرتبط بطبقة اجتماعية، أو مهنة معينة في المجتمع. ومنها: لغة الصيادين ولغة الأطباء، ولغة الصبيان، ولغة النساء وغير ذلك. وتتميز اللغة الخاصة لكل جماعة بأن لهها خصائص وسمات في المفردات، والنحو، وبناء الجمل، تميزها عن غيرها من اللهجات الاجتماعية الأخى. يمكن تحديد الطبقة الاجتماعية لمستخدم هذه اللهجة في ضوء هذه اللغة . 
Adil Elshiekh Abdalla Ahmed

ومن أسباب نشأة هذه اللهجات الفروق الثقافية والتربوية بين فئات المجتمع، ومستوى

المعيشة، وحياة الأسرة والبيئة الاجتماعية، إضافة إلى التقاليد والعادات. ومن ذلك أيضًا ما تزاوله كل طبقة من "أعمال وتضطلع به من وظائف، والآثار العميقة التي تتركها كل وظيفة ومهنة في عقلية المشتغلين بها، وحاجة أفراد كل طبقة إلى دقة التعبير وسرعته وإنشاء مصطلحات خاصة بصدد الأمور التي يكثر ورودها في حياتهم وتستأثر بقسط كبير من إنتباهم، وما يلجئون إليه من استخدام مفردات في غير ما وضعت له أو قصرها على بعض مدلولاتها للتعبير عن أمور تتصل بصناعتهم وأعمالهم" (وافي:1940) .

إن لغة القانون كما قال شوي :Shuy: 2001 كالأشعة السينية X-ray للطبيب؛ فكما

يُدرِّب الطيبب يدرب على رؤية ما لا يراه الشخص العادي من خلال هذه الاشعة؛ فكذلك رجل القانون ومن هو في حكمه، يري في اللغة القانونية مالا يراه غيره؛ ولذا فإن القانوني يدرب على أن يرى ويسمع ما لا يراه أو يعلمه غيره من عامة الناس ، ولقد قيل: إنك ستتعلم لغة جديدة عندما تدرس القانون، لكنها في الواقع أكثر تعقيدًا (Hyatt:2009). مهما يكن فإن لغة القانون باعتبارها من اللغات الخاصة تختلف عن اللغة العادية حتى أنها غدت لهجة مميزة تختلف عن اللغة المستخدمة في الامور العادية من حيث المفردات والتعابير والتراكيب والدلالة. و والسياقات، وقواعد النظم. بشكل عام، اللغة القانونية هي لغة رسمية تعتمد على قواعد المنطق والتي تختلف عن اللغة الطبيعية العادية في المفردات والصرف والصرف اللغوي ودلالات الألفاظ، بالإضافة إلى الميزات اللغوية الأخرى، التي تهدف إلى تحقيق الاتساق والصلاحية .فبما تمتاز لغة القانون عن غيرها من اللغات أي اللهجات الاجتماعية أو الطبقية؟ 
Adil Elshiekh Abdalla Ahmed

إنّ أهم ما يميزها هي التخصصية، أو التداولية أي التخصص في ما يتعلق بالقانون؛ فاللغة القانونية بكونها "لغة متخصصة مستقاة من القانون كعلم نظري وكنشاط تطبيقي، فهي تترجم الأحكام القانونية والوقائع القانونية والعلاقات والمراكز القانونية بلغة محددة خاصة بهذا العلم. وتكمن جدوى اللغة القانونية في التعبير عن الحقائق القانونية بلغة مطابقة لإرادة، ومن تم تفسير النصوص طبقًا لهذه الإرادة (الشيخلي،2014). . ولا يعني هذا التميز كما يقول علوي " أن لغة القانون أو لغة الخطاب التشريعي لغة خارجة عن الاحتكام لضوابط اللغة العامة وقواعد النظام النظام اللغوي، فهي لغة متقيدة به، وملتزمة بثوابته ومبادئه من حيث ضوابط الاستعمال وقواعد التوليد، والاشتقاق، وأساليب التعبير، وعموم القواعد الأخرى المقررة في علوم اللغة الأخرى. توظف اللغة القانونية الكثير من المصطلحات الفنية التي ليست مألوفة للشخص العادي وذلك لاختلافها عن اللغة العادية من حيث المفردات وصياغة الجمل وعلامات الترقيم التي تستخدم بطريقة مختلفة. كما يتم حشد كثير من المفردات الأجنبية في ثنايا النص ) (Haig,2024) كما تتميز بوجود اختلافات طفيفة في الإملاء والنطق والإملاء؛ جمل طويلة ومعقدة، وتحتوي في كثير من الأحيان على عبارات أو قوائم ملتصقة مع وجود ومعجم كبير ومتميز. وقد طورت المهنة تقاليد متميزة حول كيفية تفسير لغتها. من حيث الأسلوب، غالبًا ما تكون لغة القانون قديمة، رسمية، غير شخصية، وكلامية (Tiersma, 2008). كذلك تمتاز لغة القانون بالغرابة، وصعوبة الفهم للقارئ العادي من خارج مجال القانون وما يتعلق به في بعض الأحيان بسبب استخدامها عدد كبير من الكلمات والعبارات الصعبة

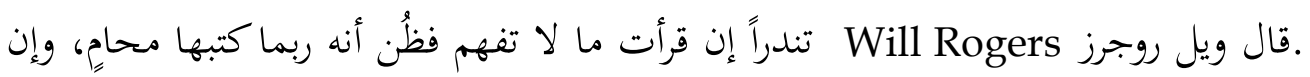
أعطيته لمحام ولم يفهم فكن علي يقين أن كاتبه محامٍ(Tiersma, 1999). إنَّ هذا التمايز ليس فقط في اللغة المكتوبة، وإنما يظهر أيضاً في أسوب كلام المحامين والقضاة. وتقول 
Adil Elshiekh Abdalla Ahmed

تيرسما : يبدو أن المحامين قد طوروا بعض المراوغات اللغوية التي لها وظيفة تواصلية قليلة، ويعملون بشكل رئيسي لتمييزهم بوصفهم أعضاء في الأسرة القانونية(Tiersma, 1999). وقد خلصت بيتر ترسما Peter Tiersma إلى القول بأن لغة القانونيين لقد تطورت بشكل طبيعي، تحت تأثير اللغات والثقافات المتنوعة، فضلاً عن التعقيد المتزايد للنظام القانوني والتحول من التواصل الشفهي في الغالب إلى الاتصال الكتابي بشكل أساسي. ومع ذلك، فإن اللغة القانونية لها تأثير، إلى حد ما، في تمكين المحامين من الاحتفاظ باحتكارهم الفعلي لتقديم الخدمات القانونية. حقيقة أن الأشخاص العاديين لا يزالون يعتمدون على المحامين لإنشاء النصوص القانونية و "ترجمتها" يجعل من الصعب على المحامين التخلي عن لغتهم المميزة(Tiersma, 1999). أوردت تيرسما Tiersma الواقعة الآتية ترسيخاً لتعقيدات لغة القانون: بعد أشهر من المشاحنات، أكمل محامي الطلاق المفاوضات مع الطرف الآخر .ثم دعا موكله جورج لينقل له الأخبار السارة. جورج: إذن ماذا جرى حتى الآن؟ المحامي

"Well, what it boils down to is that the party of the first part, to wit, George Smith, shall convey to the party of the second part and to her heirs and assigns forever fee simple to the matrimonial estate, including all property real and personal and all chattels appurtenant thereto"

$$
\begin{aligned}
& \text { جورج : لم أفهم شيئاً مما تقول. } \\
& \text { المحامي:نعم هذا صحيح. } \\
& \text { أصناف لغة القانون من حيث الموضوع }
\end{aligned}
$$

تنقسم اللغة القانونية والتي تستخدم في كافة ضروب القانون إلى ثلاثة أقسام هي:

Legislative Language لغة التشريع

Juridical Language_لغة القضاء- 
Adil Elshiekh Abdalla Ahmed

Academic legal Language اللغة القانونية الأكاديمية

اللغة التشريع Legislative Language

يقصد بلغة التشريع لغة النصوص القانونية التي تحلل لغة الوثائق مثل: قوانين البرلمان

والوصايا والدساتير، وأحكام المحاكم واستدعاءاتها وأنظمة الولايات والدوائر الحكومية. فعندما يقرأ المرء دستور بلاده يجد أن اللغة تمتاز بالغرابة. وهنا يأتي دور علم اللغة الجنائي لتذليل، وفحص هذه اللغة التي قد تختلف قليلاً عن اللغة العامة للبلاد ـيتم بناء جميع هذه الوثائق القانونية مع القواعد المورفولوجية، والنحوية، والدلالية، والبراغماتية المناسبة؛ لذلك فإن فهم الأسلوب القانوني هو واحد من العديد من المهارات التفسيرية التي يجب اكتسابها ، من أجل فهم النصوص القانونية(Bagade , 2019).

\section{Juridical Language لغة القضاء}

هي لغة الإجراءات القانونية حيث تستخدم اللغة في المحكمة، وعرض الأدلة، وتقنيات

المقابلة والاستجواب، وتسجيل البيانات، إلخ. وتبدأ من القبض على المجرم إلى إصدار الحكم النهائي؛ أي من كتابة أول بلاغ ومن ثم إصدار أمر قضائي بالقبض على المتهم، وإجراء مقابلة مع المجرمين للاستجواب والتحري حيث يبدأ تدوين البيانات التي يدلي بها المجرمون ومن له صلة بالجريمة.ويعقب ذلك تقديم الأدلة الجنائية، ويلي ذلك إعادة الاستجواب للفحص. وتشمل هذه الإجراءات أيضاً الإجراءات التي تكون مع الشهود والشاهد خبير في المحكمة لإدلائه بشهادته،والذي ينبغي أن يؤدوا قسمًا. وغير ذلك من الإجراءات ذات الطبيعة اللغوية. 
Adil Elshiekh Abdalla Ahmed

\section{Academic legal Language اللغة القانونية الأكاديمية}

هي لغة والكتب المنهجية الخاصة بتدريس القانون؛ كذلك تشمل لغة المجالات البحثية. هذه الأقسام الثلاثة ليست منفصلة عن بعضها؛ إذ إنها تتلاقى؛ فاللغة الأكاديمية هي التي تؤهل المشرع والقانوني وكل من يعمل في ميدان القانون. ولكنها تختلف من حيث المقام

$$
\text { والاستخدام. }
$$

خصوصية اللغة القانونية تمتاز اللغة القانونية في الغالب الأعم بمظاهر معينة منها ما يلي: 1. طول الجملة القانونية واعتمادها دائما على التراكيب المعقدة.

2. التباعد بين أجزاء الجملة. وهذه في بعض مكونات الجملة التي تكون غالبا متجاورة مغ بعض كالتباعد بين الفاعل والفعل أو الصفة والموصوف

3. استخدام العبارات المقيدة للمعنى بشكل مفرط لتقييد اجزاء معينة من الجملة .

4. ازدحام الجملة عادة بتفاصيل تجعل من الصعب اختراقها مما يصعب التمبيز بين

$$
\text { اجزائها الإسناد، العطف، الفصل بين أجزاء الجملة. ( صبرة 2003). }
$$

5. استخدام صيغة المبني للمعلوم في الغالب إلا في حالات عدم مناسبتها (حكيم،

6. استخدام العبارات المتلاصقة؛ وهي العبارات التي تأتي مع بعض لفائدة قانونية مثل في أو قبل، يساوي ولا يقل. ويرجع استخدام هذه إلاعبارات بهذه الطريقية لإضفاء مزيد من الإيضاح والتأكيد. 7. تستخدم اللغة القانونية قدرًا كبيرًا من النفي. قد ينتج هذا إلى حد ما عن الميل إلى التنظيم عن طريق الحظر؛ القضاة يفضلون الأوامر السلبية. 
Adil Elshiekh Abdalla Ahmed

مثال طول الجملة القانونية: إن الدول العربية الموقعة رغبة في تعزيز التعاون فيما بينها لمكافحة الجرائم الإرهابية، التي تهدد أمن الأمة العربية واستقرارها، وتشكل خطرا على مصالحها الحيوية.والتزاما بالمبادئ الأخلاقية والدينية السامية، ولا سيما أحكام

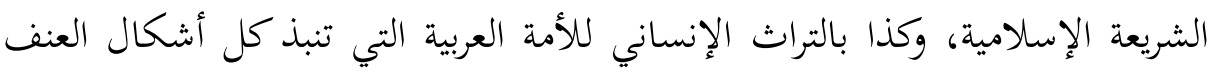
والإرهاب، وتدعو إلى حماية حقوق الإنسان، وهى الأحكام التي تتماشى معها مبادئ القانون الدولي وأسسه التي قامت على تعاون الشعوب من أجل إقامة السلام. والتزاما بميثاق جامعة الدول العربية وميثاق هيئة الأمم المتحدة، وجميع العهود والمواثيق الدولية الأخرى التي تكون الدول المتعاقدة في هذه الاتفاقية طرفا فيها. وتأكيدا على حق الشعوب في الكفاح ضد الاحتلال الأجنبي والعدوان بمختلف الوسائل، بما في ذلك الكفاح المسلح من أجل تحرير أراضيها، والحصول على حقها في تقرير مصيرها واستقلالها، وبما يحافظ على الوحدة الترابية لكل بلد عربي، وذلك كله وفقا لمقاصد ومبادئ ميثاق وقرارات الأمم المتحدة. قد اتفقت على عقد الاتفاقية، داعية كل دولة عربية لم تشارك في إبرامها إلى الانضمام إليها" ( University of .(1998 ،Minnesota. مثال التباعد بين أجزاء الجملة: يترتب على تقديم الدولة الطالبة لطلب المحاكمة، وفقا للبند (أ). من المادة السابقة، وقف إجراءات الملاحقة والتحقيق ( University .(1998 ،of Minnesota.

مثال استخدام العبارات المقيدة للمعنى بشكل مفرط لتقييد اجزاء معينة من الجملة، أو لتقييد الجملة كلها مما يصعب تأويلها لغرض غير الغرض المرجو منها. من ذلك: "يلتزم الفريق الاول بازالة اية معارضة من قبل الغير أو ورثته ويقر بانه حائز على المبيع 
Adil Elshiekh Abdalla Ahmed

بطريق مشروعة ويقر بانه سلم المباع للفريق الثاني خالي من الرهونات وغير مثقل بالديون وغير مباع وغير مثقل باي حق من الحقوق العينية وفي حالة ظهور أي دين على المباع أو رهن أو بيع يلتزم بازالته وتسديده للفريق الثاني، وخلاف ذلك فان الفريق الاول ملزم باعادة المبلغ المقبوض للفريق الثاني ويعتبر المبلغ المقبوض دين في ذمة الفريق الاول لصالح الفريق الثاني. (جامعة منيسوتا،1998).

8. ازدحام الجملة عادة بتفاصيل تجعل من الصعب اختراقها؛ مما يصعب التمييز بين أجزائها ( الإسناد، العطف، الفصل بين اجزاء الجملة ). مثال هذا النَّص التشريعي من المغرب." يجب على كل شخص طبيعي أو معنوي يمكن أن تثار مسؤوليته المدنية بسبب الأضرار البدنية أو المادية اللاحقة بالأغيار والتي تسببت فيها عربة برية ذات محرك غير مرتبطة بسكة حديدية أو بواسطة مقطوراتها أو شبه مقطوراتها، أن يغطي هذه المسؤولية بعقد تأمين مبرم مع مقاولة للتأمين وإعادة التأمين." (عدالة، 2019،

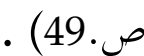

\section{العلاقة بين اللغة القانونية واللغة العامة}

إن العلاقة بين اللغة العامة في مجملها هي علاقة الخاص بالعام. ويمكن تحديد عدد من مظاهر هذه العلاقة. ومن أبرزها الصور الآتية : 1. قد يكون المصطلح القانوني أوسع مدلولاً منه في اللغة؛ لأنه يحمل دلالة أكثر من الدلالة اللغوية مثال ذلك كلمة الشَّهادةُ التي تعني لغة " خَبَرُ قاطِعِ " (الرازي، 1976صــ146). أما في القانون فتعني: "إخبار بحق للغير على الغير بلفظ أشهد، (رأفت، 1994، ص.310/1). وهذا أمر متوارد في كل اللغات؛ لأن تخصيص الدلالة يعنى إضافة معنى

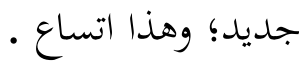


Adil Elshiekh Abdalla Ahmed

قد يكون المصطلح القانوني أضيق مدلولًا منه في اللغة. فاللغة قد تعطي معاني كثيرة .2 للفظ معين. أما القانون فيخصصه في دلاته القانونية مثال الفسخ: الفسخ: هو اعادة الحالة إلى ماكانت علية قبل التعاقد. وقد يكون نتيحة لتخلف أحد المتعاقدين. ومثال ذلك: الحضانة لغة مشتقَّة من الحِضن. جاء في القاموس المحيط " حَضَنَ الصَّبَّيَ حَضْناً وحِضانَةَ، بالكسر: جَعَلَهُ في حِضْنهه، أو رَبَّاهُ، كاحْتَضَنَهُ، و الطائرُ بَيْضَهُ حَضْناً وِحِاناً وحِضانَة" (الفيروزآبادي،2005، 1190/1). وأمَّا شرعاً فهي "حفظ صغير ونحوه عمَّا يضرّها، وتربيته بعمل مَصالحه البدنيَّة والمعنويَّة" (الدهيشي، 2014). . ومن الواضح أن المعني الاصطلاحي قد صار أضيق من المعنى اللغوي؛ لأنه قصره على الإنسان فقط .

4. قد يكون للمصطلح القانوني مدلول مغاير للمعنى اللغوي، كما هو الشأن بالنسبة الخَلْعُ:

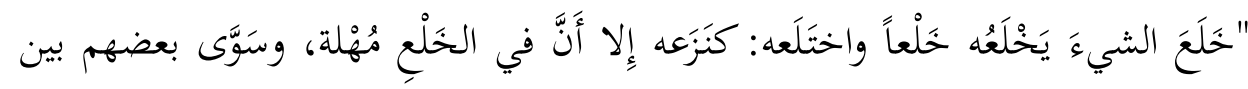

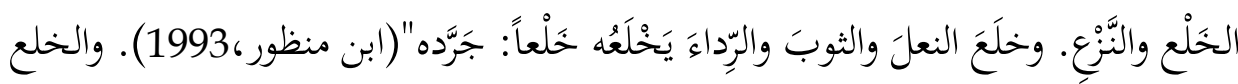
في القانون " هو دعوى ترفعها الزوجة ضد زوجها إذا بغضت الحياة معه ولم يكن من سبيل لاستمرار الحياة الزوجية وخشيت ألا تقيم حدود الله بسبب هذا البغض" (المكتبة

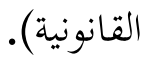
5. بعض المصطلحات التي في القانون لا وجود لها على الإطلاق في اللغة. (عبد الظاهر، 2009). مثال في اللغة الإنجليزية a fortiori التي تستخدم للقول إن شيئًا ما هو صحيح لحاله واحدة، وأكثر صحة عندما يكون في حالة أخرى.

\section{سمات اللغة القانونية من حيث الاسنخدام}

تتسم لغة لغة القانون من حيث الاستخدام بثلاث مزايا وهي : أنها لغة معيارية وإنجازية وتقنية. 
Adil Elshiekh Abdalla Ahmed

1 اللغة المعيارية Normative Language النغ

2.

3echnical Language اللغة تقنية

4. ملغة المعيارية Normative Language

توسم بأنها لغة امعيارية لأنها تستند على معيار داخل المجتمع "من خلال فرض

الواجبات وإكتساب الحقوق ،فالقانون يشمل الأخلاقيات والمعايير التي يبحث عنها الناس

من تحقيق بعض المبادئ والمفاهيم كالمساواة والإنصاف والحرية والحق". وهي إما لغة

الموافقة أو عدم الاتفاق؛ انها. يعني من خلالها نعبر عن أنفسنا على أنه مع أو ضد شيء ما

استنادا على معيار معين وضغه المجتمع؛ ولهذا فإن اللغة المستخدمة تقريرية(عبد الظاهر،

2009). أي أنها تستخدم الأسلوب المباشر الذي يكون بعيداً عن كل ما غامض مثل

الإيحاء ويكون خالياً من الصور البلاغية.

وهذا هو الأسلوب التقريري الذي من وظيفيته البيان وإزالة اللبس. ونقل

المعارف،والمعلومات،ومحاولة تقريرها كحقائق،وتأكيدها في ذهن المتلقي،.جاء في اللسان:

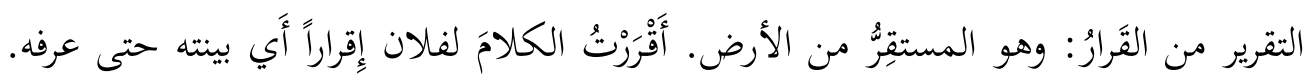
وتقريرُ الإنسان بالشيء: حمله على الإقرارِ به. وتقريرُ الشيء: جعله في قَرَارِه. وقَرَّرَُّ عنده

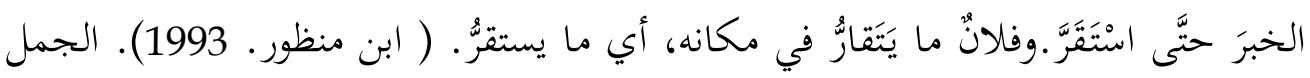
التقريرية إما تكون صحيحة أو خاطئة.

قائمة بالأفعال المعيارية

يجب، يجب، يجب، يمكن، يمكن، ويجب أن ومن الأحكام المعيارية. يجب على المكري أن يسلم للمكتري المحل والمرافق التابعة له، وكذا التجهيزات المذكورة في عقد 
Adil Elshiekh Abdalla Ahmed

الكراء. يجب أن يتوفر المحل المعد للسكنى على المواصفات الضرورية من حيث الأجزاء المكونة له وشروط التهوية والمطبخ ودورة المياه والكهرباء والماء (عدالة) . performative language ثانيا: اللغة القانونية ذات طبيعة إنجازية لا تهتم اللغة الإنجازية بوصف الحدث، وإنما تتحدث عند تنفيذ الإجراء الذي تحدده. وتعرف بأنها تلك "الأعمال التي يتم أداؤها وعملها والقيام بها أثناء النطق بالأفعال اللغوية؛ أي قد يشير معناها المعجمي إلى أحداثها التي تؤدى أثناء النطق بها، ما لم تتدخل عناصر سياقية أخرى معينة تغير من معناها المباشر" (الصراف، 2010، ص.21) ـ من أمثلة

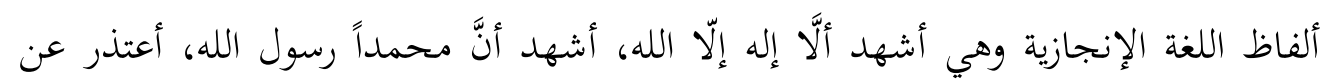
التأخير، أصر على أن تأتي معنا، أعدك أن أقرأكتابك، أوصي بإعطاء هذا المال لأخي، أعلن انسحابي، اقسم بالله العظيم، الله أكبر، استغفر الله، والحمد لله. يمكن تصنيف العديد من الأفعال كأفعال تنفيذية. عند النطق بها،أي أن لحظة النطق بالعفل هي حالة تنفيذه.وغالبا ما تستخدم في هذه الافعال الفعل المضارع. أصناف الأفعال اللّغيّة الإنجازيّ تنقسم الأفعال الإنجازية إلى:

1 تقدم الجمل التي تتضكم هذه الأفعال معلومات حول (Assertive): الإخباريّات الحقائق والآراء والمعتقدات. وتستخدم هذه الجملة بشكل شائع في الكتب والمقالات الإعلامية والتقارير ـ تنتهي هذه الجملة بنقطة. كما تؤكد هذه الجملة،

$$
\begin{aligned}
& \text { فإن الحالات أو الإعلانات تسمى أيضًا جملة تصريحية. } \\
& \text { - - وتحدد الوثيقة مهام جهاز المخابرات } \\
& \text { - - إنها لا تحب الأماكن المزدحمة. } \\
& \text { - - - يقلد شقيقها أصوات الحيوانات. }
\end{aligned}
$$


Adil Elshiekh Abdalla Ahmed

$$
\begin{aligned}
& \text { - كانت تمطر. } \\
& \text { - - الصدق هو أفضل سياسة. } \\
& \text { - - كان الطلاب يحضرون الفصل. } \\
& \text { - - - الشمس تشرق }
\end{aligned}
$$

2- و الموجّهات : وتعني الفعل اللّغويّ اللّي يدفع السّامع إلى القيام بفعل (Directives)

$$
\text { معيّن مثال: يطلب، يأمر، ينصح. }
$$

3- والإلزاميّات والتّعهّديّات : وتعني الفعل اللّغويّ الّذي يلزم المتكلّم

$$
\text { بفعلٍ أو الالنزام بشيء في المستقبل، مثال: يعد. }
$$

4- تعني الفعل اللّغويّ اللّني يعبّر من خلاله المتكلّم عن (Expressive): التّبيّيّات

سلوكه ومشاعره تجاه الغرض. مثال: يهنّئ، يعتذر، يشكر.

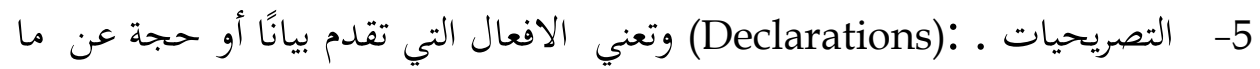

هو كائن في الحال، أو ما كان في الماضي، أو ما سيكون كذلك في المستقبل.

أي أنه يتحدث عن ما تم التأكيد على صحته . (The free Dictionary)

الاستخدام الأساسي للجملة التصريحية هو إعطاء المعلومات. بالإضافة إلى ذلك، فإن

هذا النوع من الجمل له استخدامات أخرى عديدة. إذ يمكن استخدامه للتعبير عن الموافقة

$$
\begin{aligned}
& \text { والشكر وطلب المعلومات وحتى لإعطاء الأوامر. } \\
& \text { حكم القاضي على المتهم. } \\
& \text { - - ستقد الجلسة في يوم كذا. } \\
& \text { - - تنظر الآن المحكمة قضية. }
\end{aligned}
$$

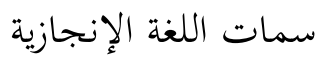


Adil Elshiekh Abdalla Ahmed

$$
\text { تمتاز اللغة الإنجازية بعدد من السمات منها: }
$$

1 - 1 انها منطوقة، ومعناها العمل الذي ينجز بها

2. النطق بالجملة هي جزء من إنجاز الفعل.

3. هذه الأفعال لا تصف شيئاً ولا تقره فلا يحصل منها على معلومات؛ إذ إنها ليست

$$
\text { لازمة الفائدة }
$$

4. لا نحكم عليها بالصدق أو بالكذب .

$$
\text { 5. تأخذ شكلاً نحوياً معيناً. (الصراف، } 2010 \text { ص. 23- 24). }
$$

ثالثا: اللغة القانونية ذات طبيعة تقنية

اختلف الباحثون حول اعتبار لغة القانون لغة تقنية، فالبعض يرى أنها جزء لا يتجزء عن

اللغة العربية باعتبارها اللغة الأم، في حين يرى البعض الأخر أنها لغة تقنية ويبرز هؤلاء قولهم بمجموعة من الحجج والبراهين منها:

تتسم اللغة القانونية بالدقة المتناهية ؛ إذ يحرص المشتغلون بالقانون بشدّة على انتقاء العبارات والمفردات القانونية المرّزة في المذكرات المرسلة إلى المحاكم، أو في الاحكام التي تصدر، أو العقود التي تكون بين الناس. فمثلا يستخدم في العقد تعبير (التزم بتسليم، أو يلتزم بدفع). بدلاً من تعهد بتسليم، أو يتعهد بتسليم ذلك لأن العقد يحتوي على التزامات متقابلة، فضلاً عن أن أحكام العقد مستقاة من النظرية الشهيرة في القانون المدني التي تدعى: نظرية الالتزام وليس نظرية التعهدات ففي عقد البيع نقول (باع). ولا نقول (تنازل). لأن التنازل قد يكون بدون مقابل، ويحمل معنى الهبة أو التبرع. ( الشعال، 2016). قواعد هامة في الكتابة القانونية 
Adil Elshiekh Abdalla Ahmed

ولأهمية اللغة القانونية ولدورها في تكوين شخصية القانوني وتحديد نجاحه فينغي على المشتغل بالقانون الاعتناء بها وأن يتعامل معها بدقة؛ نظرًا لأن معنى الكلمات أمر حاسم للغاية في مهنة القانوني. وهذه بعض القواعد الإجرائية التي يمكن أن يهتدي بها كاتب النص القانوني أياً كان موضوعه القانوني:

1. الاعتناء بالقواعد اللغوية وعلامات الترقيم، لأنها حاسمة، ومهمة في إبراز المعنى: فعبارة: الشخص الذي يترك 50,000 دولار" لكل من أطفالي الذين اهتموا بي ".لها معنى مختلف عن عبارة "الشخص الذي يترك 50,000 دولار" لكل من أطفالي، الذين اهتموا بي. ففي الأولى تقسم الأموال على كل الأبناء لأنهم كلهم قد اهتموا به. أما في الثانية فتشمل فقط الأطفال الذين اهتموا به. إذن فكل محام يقوم بصياغة الوصايا(Hyatt) . 2. استخدام لغة تتصف بخصائص معينة كالسّلامة، والسّلاسة، والوضوح، والدقة، والقطعية، بعيدةً عن الأخطاء والتكلف، والغموض، والتعقيد.إن مقتضى الحال وطبيعة النص التشريعي يوجبان على المشرع أن يكتب بأسلوب تتوفر فيه السمات السابقة، فضلاً عن ضرورة ألا تكون المفردات قابلة لأكثر من تأويل، وألا تكون التراكيب اللغوية تحتمل أكثر من وجه عند تفسير النص" (الأحمد ، 2017). 3. التزام الإيجاز والوضوح. ويقصد بالإيجاز عدم الإطناب والاسترسال. وأن يكون اللفظ والتركيب على قدر المعنى والمطلوب فهمه؛ أي ألا يكون إيجازاً مخلاً بالغرض أو إطناباً يؤدي إلى معني زائدة غير مطلوبة "لأن الإيجاز يضبط الأفكار ويؤدي إلى الوضوح. فيتم استخدام الكلمات والعبارات القانونية التي تدل على الفكرة المقصودة بما يكشف عن الغاية منها. كما أنه يرفع عن الحاكم عبء الإسهاب والإطالة في التعاليل وسرد الوقائع التي لا طائل منا ـيؤكد ذلك السنهوري بقوله : "يجب أن تكون 
Adil Elshiekh Abdalla Ahmed

لغة التقنين واضحة ودقيقة، فاللغة المعقدة تجعل القانون مغلقاً، كما أن اللغة غير الدقيقة تجعل القانون مبهماً" (السنهوري، 1933، ص33). الابتعاد عن الصور المجازية؛ لأن المجاز مدعاة للتأويل. (بشير،2005) والتأويل مدعاة إلى ضياع الحقوق القانونية؛ لأن المعاني تتشعب؛ مما يؤدي إلى اللبس. ونقل العبودي عن محمد العربي المجبوذ قوله: "لا يحتاج عند تحرير أحكامه إلى الجمل الرنانة أو ما يداعب الأذن على غرار الكاتب الروائي أو الصحفي أو الشاعر، بل عليه أن يستعمل في قراراته العبارات المفيدة والمنصبة على الوقائع مع مراعاة الترتيب في التفكير والتعليل. إنجودة القرارات القضائية ليست مرتبطة إطلاقا بالتطويل والإسهاب، فقيمة الحكم لا تقاس بعدد السطور. يتعين أن يكون القرار متسما بالإيجاز مع اجتناب التفاصيل" (العبودي، 2016). (2016)

5. استخدام الأسلوب العلمي فإن أسلوب القانوني ينبغي أن يكون أسلوباً علمياً متأدباً تبرز فيه الحقائق العلمية بوضوح (معن، 2005). 6. أن يكون أسلوب القانوني علمياً متأدباً، لا أدبياً، بين الأسلوب الأدبي والأسلوب المتأدب. إن الأسلوب الأدبي هو الذي يسلك طريقة الأدباء في النظم فيعني بالنواحي البيلاغية والأخيلة، بنما يكو ن يراعي الأسلوب المتأدب ذلك الذي ي كون متقيدا بحسن الخلق ؛أي يتبع أسلوب البرهنة والتعليل. ومن خصائص هذا الأسلوب . إبراز الحقائق بدقة ووضوح. يخاطب العقل والمنطق ولذا يجب دعم الرأي بالأدلة والبراهين • 
Adil Elshiekh Abdalla Ahmed

• ينبغي أن يكون أسلوب القانوني أسلوباً علمياً متأدباً يبرز فيه الحقائق بدقة ووضوح فالكلمة في الوثيقة القانونية تكتسب معنى مراتبطأ بالسياق الذي ترد فيه.

7. الابتعاد عن استخدام الكلمات التي لها دلالات قديمة لا تنناسب العصر مثل العبارات التالية في المواريث والتي أطلقت باعتبار جلب الإرث من عدمه لمن هم في حكم

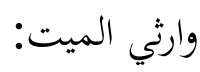
الجد الفاسد ، وهو من يتصل إلى الميت بأم

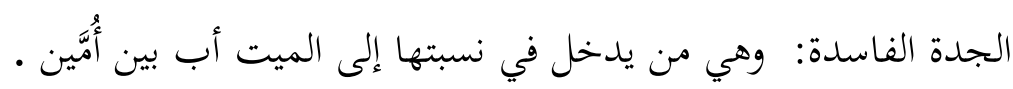
الأخ المبارك : و هو الذي لولاه لسقطت أخته.

8. الابتعاد عن الصياغة الضعيفة واستخدام المصطلحات التي قد لا تدل على المراد بدقة ويظل النص عرضة للاجتهاد مثال كلمة (تأديبي). الوارد في المجالس التأديبة ). فهل يراد بها مجالس الانضباط، بينما يتسع مفهوم لفظ (تأديبي ).؛ ليدل على أكثر من معنى كالارتقاء بالجانب الأخلاقي. والذوق العام(بسير: 2005) . 9. عدم استخدام مصطلحات، فرنسية أو إنجليزية. 10. الالتزام بوحدة الأسلوب في البناء بحيث يعكف شخص واحد غلى الكتابة حتى لا يتداخل أسلوبان في نص واحد. 11. الضبط بالشكل في حالات الالتباس؛ فالحجرة الإعرابية قد تغير المعنى، وبالتالي قد يتغير الحكم. 
Adil Elshiekh Abdalla Ahmed

12. تفادي الصيغ الشخصية فلا يستخدم ضمير المتكلم (أنا وأنت). واستخدام ضمير الغائب. وهذا أمر منطقي فيالقوانين، لأن النظام الأساسي "لا يتحدث" فقط مع مرتكبي الجرائم الجنسية، ولكن للشرطة والمحاكم؛ لذلك قد تكون غير مناسب أو غامض. في مكان آخر (كما هو الحال في ميل القضاة إلى الإشارة إلى أنفسهم على أنهم المحكمة وليس أنا).، فإنه يخلق انطباعًا بالموضوعية والسلطة، مما يساعد على إضفاء الشرعية على النظام القانوني. تبدو اللجان متعددة القضاة أقل ترددًا في استخدامنا، وسوف تستخدم هذا الضمير للإشارة إلى القرار الذي اتخذه سابقوه منذ فترة طويلة. هنا، يشدد الشخص الأول على استمرارية القانون وتاريخه. 13. الالتزام بوحدة الأسلوب بمعنى ألا تكون المواد القانونية للتشريع تختلف في البناء اللغوي للنص بحيث يشعر القارئ أن هذا التشريع قد صاغَهُ أكثر من شخص، ويحدث هذا في التشريعات الكبيرة، إذ يتم تقسيم المواد والأحكام بين المختصين، وعند دمج المواد يظهر للقارئ أن التشريع قد كُتبَ بأكثر من أسلوب، لذلك يفضل في مثل هذه الحالات أن يُعِدَّ المختصون أحكامَ التشريع المتفرقة، ويقوم شخص واحد بالصياغة النهائية للتشريع. 14. ضبط علامات الإعراب في المواضع التي يلتبسُ فيها المعنى على القارئ، ولا سيما في نهاية بعض الكلمات(الأحمد) .

15. تعزيز لغة القانون بالوضوح والإيجاز من خلال مفردات قانونية محددة 199ersma)

الخلاصة

تناول هذا المقال اللغة القانونية، وبيَّن خصوصيتها، وعلاقتها باللغة العامة، وأنواعها، ثم تعرض لبعض القواعد العامة للكتابة القانونية. وقد أبان أن اللغة عنصر مهم من مكونات 
Adil Elshiekh Abdalla Ahmed

القانون؛ فبدونها لا يوجد قانون؛ فالقوانين التي هي بمثابة مجموعة من القواعد التشريعية، تصاغ باللغة، وتظل محكومة بها. كذلك أبان أن العناية بأحكام المرافعات، وجودتها أدى إلى بروز نوع من اللغة الخاصة تسمى لغة القانون Language Of The Law أو اللغة القانونية Legal Language. وهذه اللغة القانونية - باعتبارها من اللغات الخاصة - تختلف عن اللغة العادية عنها من حيث المفردات والتعابير والتراكيب والدلالة، والسياقات، وقواعد النظم. كذلك تمتاز لغة القانون بالغرابة، وصعوبة الفهم للقارئ العادي من خارج مجال القانون وما يتعلق به في بعض الأحيان بسبب استخدامها عدد كبير من الكلمات والعبارات الصعبة. تنقسم اللغة القانونية إلى ثلاثة أقسام هي: لغة التشريع Legislative Language ، ولغة

Academic legal Language القضاء Juridical Language ، واللغة القانونية الأكاديميةكية وتمتاز اللغة القانونية من حيث التركيب بمظاهر معينة منها: طول الجملة واعتمادها دائما على التراكيب المعقدة.والتباعد بين أجزاء الجملة، وازدحام الجملة بتفاصيل تجعل من الصعب اختراقها مما يصعب التمييز بين أجزائها الإسناد، العطف، الفصل بين أجزاء الجملة، وورغم خصوصية اللغة القانونية ، إلا إنها تتصل بالعربية العامة اتصال العام بالخاص ـ لكي تؤدي هذه اللغة دورها فيجب الإلتزام ببعض القواعد منها: الاعتناء بالقواعد اللغوية وعلامات الترقيم، الإيجاز والوضوح. والابتعاد عن الصور المجازية؛. وأن يكون الأسلوب علمياً متادباً لا أدبياً، خيالياً. طذلك ينبغي استخدام اللغة العصرية المضبوطة بالشكل الخالية من المصطلحات الأجنبية.

\section{المصادر والمراجع}

Abū Al-'Atam, F. (2014). Al-Luġä̈ Al-' Arbīyä̈ Wa Daūruhā F̄̄ Al-Tašrī' Wālqaụā'. Afkar, 300, 59-67.

Al-Aḥmad, S. I. (2017). Hașā'iș Lug̉ä̈ Al-Tašrī'āt. Retrieved February 11, 2021, from albayan.ae website: https: / / www.albayan.ae/ across-the-uae/news-andreports/2017-03-16-1.2888008 
Al-ğaḍlānī, M. S. (2009). Al-Lugaä al-Qānūnīyyä̈ Fī Ma'zaq. Retrieved April 20, 2021, from aleqt.com website: https://www.aleqt.com/2009/11/15/article_301632.html

Al-Rāzī, M. A. B. (1976). Muḥtār Al-Ṣaḥāḥ. Cairo: al-Haaï Al-Mișrīyä̈ Al-'āmmä̈ Lil kitāb.

Al-Shaikhli, A. Q. (2014). Al-Ṣìāàgä̈ Al-Qānūnīyä̈. Jordan: Dar alTsaqafah.

Alaoui, H. I. (n.d.). Baina al-Lisānīyāt Wa al-Qānūn. Retrieved February 2, 2021, from imamu.edu.sa website: https://units.imamu.edu.sa/rcentres/Arabic_Literatures/Docu ments/coArabiclanguage/8. دافيظ إسماعيلي علوي.pdf

Bagade, P. R. (2018). Importance of Forensic Linguistics In Crime Investigation. In K. V. Pandey (Ed.), Twelfth Students' Conference of Linguistics in India. Wardha: Department of Linguistics and Language Technology, MGAHV, Wardha.

Bašīr, M. A. (2005). Lugaä Ahlu Al-Qānūn Al-Tahrīrīyä̈ Wāšafawiyä̈. Buhuth Mustaqbaliya Scientific Periodical Journal, 3(4), 171-230.

El-Sanhuri, A. E.-R. (1933). Wuğūb Tanqīh al-Qānūn al-Madn̄̄ al-Mișrī, Wa 'Ala Aī Asās Yakūn Hadāa al-Tanqīh. Mağalä̈ Al-Qānūn Wa Iqtișād, 6(142).

Fairūzābādī. (2005). Al-Qamus Al-Muhit (8th ed.; M. N. Al-'Irqasūsī, Ed.). Beirut: Mu'sasä̈ al-Risālä̈ Lil țibā'ä̈ Wa Al-Našr Wa alTaūzī' .

Fāris, I. (1958). Kitāb Fatīyā Faqīh al-'Arab (Husīn Alī Maḥūūz, Ed.). Damascus: Mațbū'āt Al-Mağma' Al-'Iilmī al-' Arabī.

Farlex. (2003). Declarative Sentences. Retrieved April 5, 2021, from thefreedictionary.com website: https:// www.thefreedictionary.com/Declarative-Sentences.htm

Haigh, R. (2009). Legal English. New York: Routledge-Cavendish.

Hakīm, Q. Q. (2016). Dirāsä̈ Al-Tağribä̈ Al-ğazāìrï̈ fi Ta 'dìl al-Dasātīr (University of Djelfa). University of Djelfa. Retrieved from http:/ /dspace.univ- 
djelfa.dz:8080/xmlui/bitstream/handle/123456789/2177/التجرية الجزائرية في تعديل الدستور.pdf?sequence=1\&isAllowed=y

Hyatt, S. (2020). Legal Language. Retrieved February 12, 2021, from Sturm College of Law website: https:// www.law.du.edu/index.php/law-school-learningaids/legal-language

'Uthmān, M. R. (1994). al-Niẓām al-Qaḍā'i fì al-Fiqh al-Islāmì. Kuwait: Dar al-Bayan.

Ibn Manzūur. (1993). Lisān al- 'Arab (3rd ed.). Beirut: Dār Ṣādr Linšr.

Shuy, R. W. (2003). Forensic Linguistics. In M. Aronoff \& J. Ress-Miller (Eds.), The Handbook of Linguistics (pp. 683-691). Malden- Oxford Victoria: Blackwell Publishers Ltd. https:// doi.org/10.1002/9780470756409.ch30

Tiersma, P. (2008). The nature of legal language. In J. Gibbons \& M. T. Turell (Eds.), Dimensions of Forensic Linguistics. Amsterdam: John Benjamins Publishing Company.

Tiersma, P. M. (1999). Legal Language. Chicago: University of Chicago Press.

University of Minnesota. (1999). Al-Ittifāqīyä̈ al-'Arabīyä̈ Limukāfaḥä̈ al-Irhāb. Retrieved April 3, 2021, from hrlibrary.umn.ed website: http://hrlibrary.umn.edu/arabic/aterroh.html

Wāfī, A. ‘ A. (1940). al-Lahğāt al-Iğtimā'īyaü. Mağalä̈ Al-Risālä̈, 386. 